\title{
TRANSPLANTE RENAL NA DOENÇA DE FABRY
}

Euler Pace Lasmar ${ }^{1}$, Marcus Faria Lasmar ${ }^{2}$, Adalberto Fernandes Nogueira ${ }^{3}$, Leonardo Faria Lasmar ${ }^{4}$, Fernando Oréfice ${ }^{5}$, Patrícia Vasconcelos Lima ${ }^{6}$, Luiz Flávio Couto Giordano ${ }^{7}$, Heloisa Reniers Vianna ${ }^{8}$

Trabalho realizado na Faculdade de Ciências Médicas - Hospital Universitário São José, Universidade Federal de Minas Gerais e Hospital Mater-Dei, Belo Horizonte, MG

\section{INTRODUÇÃO}

A doença de Anderson-Fabry (angiokeratoma corporis diffusum universale) é uma doença rara, resultante da deficiência da enzima alfa-galactosidade A ( $\alpha-G A L)$, determinando o acúmulo progressivo de substâncias lipídicas (ceramida) no interior do endotélio e músculos lisos de vasos sanguíneos ${ }^{1}$. Isto determina o comprometimento progressivo de vários órgãos, como rins, coração, sistema nervoso central e pele².

Herdada como caráter recessivo ligado ao cromossomo X, apresenta uma prevalência de 1: 40.000/ homens, sendo que a forma clássica ocorre em homens homozigotos ${ }^{1,2}$.

Os sintomas surgem na infância e adolescência, como o aparecimento de acroparestesias, angioqueratomas, dores articulares, córnea verticilata e hipohidrose. $\mathrm{Na} 3^{a}$ e $4^{a}$ décadas da vida ocorre aumento dos sintomas, caracterizados pelo comprometimento progressivo do sistema vascular, levando a alterações renais, cardíacas e cerebrais ${ }^{3,4}$.

A doença renal leva a um quadro de hipertensäo arterial, proteinúria e hematúria, podendo evoluir para insuficiência renal crônica, que constitui a principal causa de morte ${ }^{5}$.

O transplante renal constitue o método de escolha para a terapia renal substitutiva porque além de restaurar a função renal aumenta a eliminação da ceramida através de excreção ou degradação. Além disso, o rim transplantado pode produzir a enzima $\alpha-G A L$, corrigindo o defeito metabólico ${ }^{6,7,8,9}$. Entretanto, alguns trabalhos mais recentes mostram que 0 transplante apresenta elevada mortalidade, decorrente de infecções e complicações dos órgãos comprometidos, além da possibilidade da recorrência da doença no enxerto ${ }^{10,11,12}$.

Existem poucas publicações a respeito da sobrevida do enxerto à longo prazo após transplante renal em pacientes com doença de Fabry ${ }^{10}$. Não encontramos na literatura brasileira nenhum caso publicado.

\section{Relato do Caso}

RMA, 42 anos, casado, dois filhos. Aos 11 anos de idade (1975) começou a apresentar dores articulares nas mãos e pés, associadas à hipohidrose. Procurou médico, que fez o diagnóstico de febre reumática, e prescreveu benzetacil.

Aos 18 anos, após sentir dores no peito, procurou cardiologista que diagnosticou através de ecocardiograma, degeneração mixomatosa e prolapso da válvula mitral (sic). Nesta época começou a observar pequenos pontos avermelhados nas mãos e quadris.

Aos 42 anos procurou vários médicosclínicos, reumatologistas e dermatologistas que não fizeram o diagnóstico e classificaram a doença como psíquica.

Em agosto de 2000, com 36 anos de idade começou a apresentar edema maleolar, náuseas, vômitos e fadiga intensa, quando foi detectada insuficiência renal. Foi submetido à biópsia renal em São Paulo, que revelou esclerose glomerular focal e encaminhado para Belo Horizonte, onde residia.

Iniciou hemodiálise em 12/05/2001 e foi submetido à transplante renal em 16/07/2001, tendo a esposa como doadora. Não apresentou qualquer anormalidade no pós-operatório imediato, tendo recebido imunossupressão com tacrolimo, azatioprina e prednisona. Um ano após transplante apresentou quadro de citomegalovirose, tratada e curada com ganciclovir.

Após o transplante renal houve acentuação das dores articulares e hipohidrose, com incapacidade para o trabalho, sendoencaminhado para vários reumatologistas, sem diagnóstico. Na perícia médica era sempre definido como neurótico.

Dois ecocardiogramas feitos antes e após o transplante mostraram insuficiência mitral decorrente à degeneração mixomatosa dessa válvula.

Em maio de 2005, foi feita a suspeita de Doença de Fabry, confirmada através da dosagem da enzima $\alpha-G A L$ no plasma em exame de papel de filtro $(0.03 \mathrm{umol} / \mathrm{l} / \mathrm{h})$ e nos leucócitos

1. Professor Titular de Nefrologia da Faculdade Ciências Médicas de Minas Gerais. Coordenador do Transplante Renal do Hospital Universitário São José e Hospital Mater Dei, Belo Horizonte, MG

2. Médico assistente da Disciplina de Clínica Médica na Universidade Federal de São Paulo - UNIFESP; Médico Nefrologista do Hospital Universitário São José da Faculdade Ciências Médicas de Minas Gerais e Médico Nefrologista e Intensivista do Hospital Mater Dei, Belo Horizonte, MG

3. Médico Residente em Nefrologia do Hospital Universitário Sâo José da Faculdade Ciências Médicas de Minas Gerais e Médico do Departamento de Clínica Médica do Hospital Municipal Odilon Behrens, Belo Horizonte, MG

4. Médico Pós-Graduando em Nefrologia do Hospital da Beneficência Portuguesa de São Paulo, São Paulo, SP

5. Professor Titular de Oftalmologia da Universidade Federal de Minas Gerais - UFMG, Belo Horizonte, MG

6. Professora Assistente de Nefrologia da Faculdade Ciências Médicas de Minas Gerais, Belo Horizonte, MG

7. Médico Nefrologista do Hospital Universitário São José e Hospital Mater Dei, Belo Horizonte, MG

8. Médica Nefrologista do Hospital Universitário São José, Belo Horizonte, MG 
(enzima não detectável). Foi encaminhado à oftalmologista que detectou presença de córnea verticilata.

Atualmente, não apresenta alterações no exame de urina e a função renal avaliada pela depuração da creatinina é de $56 \mathrm{ml} / \mathrm{min}$.

\section{Discussão}

A doença de Fabry é uma doença de depósito lisossômico, de herança ligada ao cromossomo $\mathrm{X}$, afetando, portanto, principalmente pacientes do sexo masculino. Os homens com a doença (homozigotos) passam o gene defeituoso para todas as filhas, mas não passam para nenhum filho homem. As mulheres portadoras (heterozigotas), que às vezes têm manifestações clínicas, possuem $50 \%$ de probabilidade de transmitir o gene deficiente tanto para os filhos, como para as filhas.

A deficiência na atividade da enzima $\alpha-G A L$ A resulta no acúmulo progressivo da globotriaozyl-ceramida (GL-3) e dos glicoesfingolípides nos lisosomos do endotélio vascular, bem como das células epiteliais e musculares lisas de todos os vasos do corpo humano. Com o decorrer dos anos, o progressivo envolvimento endotelial dos vasos pode determinar insuficiência renal, cardiopatia e acidente vascular cerebral. O comprometimento renal inicial caracteriza-se pelo acúmulo de glicoesfingolípides nas células endoteliais e epiteliais dos glomérulos e espaço de Bowmann, e no epitélio das alças de Henle e túbulos contornados distais. Concomitantemente os vasos renais são envolvidos progressivamente, com infiltração de histiócitos e fibrócitos no interstício, até determinar a esclerose total do parênquima renal.

$\mathrm{Na}$ forma clássica da doença, observa-se no sedimento urinário durante a infância e adolescência, proteinúria, cilindros hialinos e lipoides birrefringentes com aspecto de "Cruz de Malta". A função renal deteriora-se gradualmente, e a uremia geralmente surge entre a $3^{a}$ e $4^{a}$ década da vida.

A insuficiência renal constitui a mais frequente e importante complicação tardia da doença e a principal causa de óbito. 0 transplante renal representa a melhor alternativa da terapia renal substitutiva, porque, além de restaurar a função renal pode proporcionar outro benefício: a elim inação da GL3 através da excreção em degradação, com a consequente correção do defeito metabólico ${ }^{1}$. Entretanto, algumas publicações mostram que a doença pode recorrer nos rins transplantados ${ }^{10,11,12,15}$.

Os sintomas da doença, como acroparestesias, dores articulares e hipohidrose também costumam melhorar após o transplante renal, o que não ocorreu nesse paciente, que passou a apresentar dores articulares mais intensas. 0 diagnóstico da doença é confirmado bioquimicamente pela demonstração de atividade da enzima $\alpha$-GAL muito baixa ou indetectável no plasma, no soro, nos leucócitos, nas lágrimas ou no tecido biopsiado, utilizando-se um teste com um substrato sintético de $\alpha$-GAL e com $\mathrm{N}$-acetilgalactosamina na mistura da reação, para inibir a atividade da enzima $\alpha$-galactosidade $\mathrm{B}^{16}$. Esse teste foi introduzido recentemente no Brasil, o que possibilitou o diagnóstico de certeza deste paciente.

Foram realizados exame oftalmológico e dermatológico da mãe, uma irmã, dois irmãos e dois filhos (Tabela 1), bem como dosagem da atividade da enzima $\alpha-G A L$ no plasma e leucócitos isolados (Tabela 2). A mãe apresenta doença renal crônica (grau III) e teve acidente vascular cerebral isquêmico há 30 anos. A irmã foi submetida à transplante renal em São Paulo em 1997 e os dois irmãos apresentam sintomas típicos da doença (Tabela 1 ), bem como atividade da enzima $\alpha-G A L$ diminuída no plasma (Tabela 2). Os dois filhos do paciente não apresentam evidências clínicas ou laboratoriais da doença.

Nesta série de casos em uma família, todos os filhos apresentam a doença. Importante ressaltar que todos com a doença apresentaram córnea verticilata (Figura 1), e alteração na dosagem em leucócitos isolados (Tabela 2).

0 angioqueratoma foi observado no paciente e em outros dois irmãos (Figura 2).

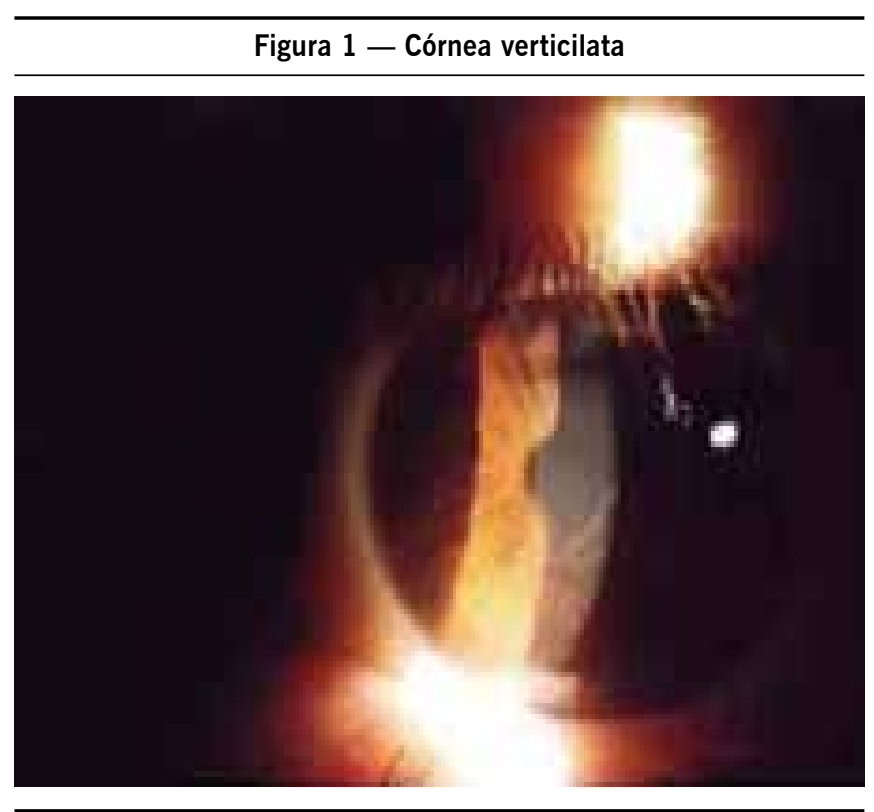

Figura 2 - Angioqueratoma

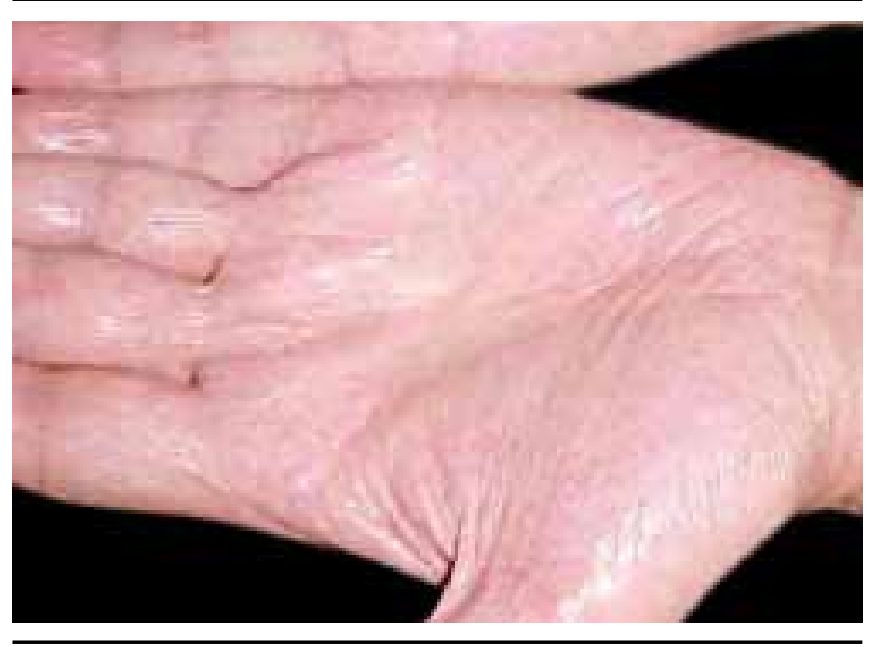


Tabela 1. Presença de alterações clínicas da doença nos familiares

\begin{tabular}{|c|c|c|c|c|c|c|c|}
\hline \multirow{2}{*}{ Alteração } & \multirow{2}{*}{ Angioqueratoma } & \multirow{2}{*}{ Hipoidrose } & \multirow{2}{*}{$\begin{array}{c}\text { Córnea } \\
\text { verticilata }\end{array}$} & \multirow{2}{*}{$\begin{array}{c}\text { Acro- } \\
\text { parestesia }\end{array}$} & \multicolumn{3}{|c|}{ Anormalidades } \\
\hline & & & & & Renal & Cardíaca & Cerebral \\
\hline Mãe & & & $x$ & & $x$ & $x$ & $x$ \\
\hline |rmão1 & & $x$ & $x$ & $x$ & & $x$ & \\
\hline Irmão 2 & $x$ & & $x$ & $x$ & $x$ & $x$ & \\
\hline Irmão 3 & & $x$ & $x$ & $x$ & $x$ & & \\
\hline Irmão 4 & $x$ & $x$ & $x$ & $x$ & $x$ & $x$ & \\
\hline
\end{tabular}

Tabela 2. Dosagem da atividade da enzima alfa galactosidase no plasma e em leucócitos isolados nos familiares

\begin{tabular}{|c|c|c|c|c|}
\hline & & & Dosagem da Atividade da & Enzima Alfa-Galactosidase \\
\hline & $\begin{array}{c}\text { Data } \\
\text { Nascimento }\end{array}$ & $\begin{array}{l}\text { Data } \\
\text { Exame }\end{array}$ & $\begin{array}{c}\text { Plasma } \\
\text { (Ref.: }>2,7 \text { umol/L/h) }\end{array}$ & $\begin{array}{c}\text { Leucócitos } \\
\text { (Ref.: }>1,4 \text { umol/mg//h) }\end{array}$ \\
\hline Mãe & $9 / 11 / 35$ & $18 / 7 / 05$ & 0,54 & 18,4 \\
\hline |rmãol & $5 / 3 / 60$ & $18 / 7 / 05$ & 0,16 & ND \\
\hline Irmão 3 & $10 / 9 / 62$ & 18/7/05 & 0,53 & ND \\
\hline Irmão 4 & $10 / 3 / 64$ & 19/5/05 & 0,03 & ND \\
\hline
\end{tabular}

Um dos diagnósticos diferenciais da doença é com a febre reumática, e, neste caso, tanto o paciente bem como os irmãos foram diagnosticados e tratados como tal. Como não havia na anamnese inicial deste paciente, história familiar da doença, o diagnóstico correto foi tardio.

Interessante observação foi que a córnea verticilata constituiu-se no único achado clínico presente em todos os pacientes. Este tipo de alteração pode ocorrer também com o uso de medicamentos como fenotiazina, cloroquina, amiodarona e indometacina e é descrita como marcador do estado portador ${ }^{17,18}$, mas nesta família apresenta-se como marcador da doença.

Até recentemente, o tratamento da doença de Fabry era inespecífico e paliativo, dirigida apenas às complicações da doença. Após extensos estudos pré-clínicos e clínicos ${ }^{19,20}$ foi comprovada a segurança e eficácia da agalsidade beta ( $\alpha-G A L$ humana recombinante), tendo sido escolhido o esquema de reposição por infusão venosa ${ }^{20}$.

Atualmente, o paciente apresenta função renal preservada (depuração da creatinina de $56 \mathrm{ml} / \mathrm{min}$ ), ausência de alterações urinárias, hipertensão arterial ou cardiopatia grave. Persiste com dores articulares e deverá iniciar tratamento de reposição com agalsidase beta.

\section{Conclusão}

A doença de Fabry deve ser suspeitada em pacientes portadores de doença renal associada a alterações cardíacas, dores articulares, lesões dermatológicas (angioqueratomas) e córnea verticilata. O transplante renal, até o presente momento, produziu uma excelente reabilitação do paciente, sem evidências de recorrência da doença, e constitui-se na melhor opção terapêutica da insuficiência renal determinada pela doença de Fabry, em concordância com os achados da literatura, embora sejam descritos casos de recorrência da doença após alguns anos, o que não ocorreu com este paciente.

\section{REFERÊNCIAS}

1. Anderson W. A case of angiokeratoma. Br J Dermatol.1898;10:113.

2. Brady RO, Gal AE, Brasley RM, Martenson E. Enzymatic defect in Fabry's disease: ceramida trihexoidase deficiency. N Engl J Med. 1967;276:1167.

3. Blom D, Spelier D, Linthosrt GE, Doriker-Koopman WG. Recombinant Enzyme Therapy for Fabry Disease: absence of editing of human a galactosidase A mRNA. Am J Hum Genet. 2003;72:23-31.

4. Garman SC, Garboczi DN. The molecular defect leading to Fabry disease: structure of human alpha-galactosidade. J Mol Biol. 2004;337:319-35.

5. Meromi M, Sessa A, Battini G, Tazzari S, Tarelli LT. Kidney involvement in Anderson-Fabry disease. Contrib Nephrol. 1997;122:178-84.

6. Sketh KJ, Roth DA, Adams MB. Early renal failure In Fabry's disease. Am J Kidney Dis. 1983;2:651-4. 
7. Desnick RJ, Simmons RL, Allen KY, Woods JE, Anderson CF, Najarian JS, et al. Correction of enzymatic deficiencies by renal transplantation: Fabry's disease. Surgery 1972;72:203-11.

8. Maizel SE, Simmons RL, Kjellstrand:C, Fryd DS. Ten Year experience in renal transplantation for Fabrys disease. Transplant Proc. 1981;13:57-9.

9. Gantenbein H, Bruder E, Burger HR, Briner J. Recurrence of Fabry's disease in a renal allograft 14 years after transplantation. Nephrol Dial Transplant. 1995;10:287-9.

10. Kolodny EH. Case report of mass gen hospital. Case2. N Engl J Med. 1984;310:106-14

11. Friedlander MM,Kopolovic CJ,Rubinger D,Silver J. Renal in Fabry's disease eight years after successful renal transplantation. Clin Nephrol 1987;27:206-211.

12. Bannwart F Morbus. Fabry: Licht Und Elektronenmikroskopischer Herzbefund 12 Jahre nach erfalgreicher Nieren transplantation. Schwer Med Wsch. 1982;112:1742-7.

13. Clarke JTR, Guttman RD, Wlfe LS, Beandoin JG, Morehouse DD. Enzyme replacement therapy by renal allotransplantation in Fabry's disease. N Engl J Med. 1972;287:1215-8.

14. Spluce MW, Mackinnon KE, Burgess JK, D Éntremont DM..Failure to correct the metabolic defect by renal allotransplantation in Fabry's disease. Ann Intern Med. 1976;84:13-6.

15. Mosnier JF, Degott C, Bedrossian J, Molas G. Recurrence of Fabry's disease in a renal allografteleven years after successful renal transplantation. Transplantation. 1991:51:759-62.

16. Mayes JS, Scheerer JB, Sifers RN, Donaldson ML. Differencial assay for lysosoma alpha-galactosidase in human tissues and its application to Fabry's disease. Clin Acta 1981;112:247-51.
17. Nguyen TT, Gin T, Nicholls K, Low M, Galanos J, Crawford A. Ophthalmological manifestation of Fabry disease: a treatment centre. Clin Exp Ophthalmol 2005;33:164-8.

18. Hirano K, Murata R, Miyagawa A, Teresa KH. Histopathologic findings of cornea verticillata in a woman heterozygous for Fabry's disease. Ovid Herano Corea. 2001;20:233-6.

19. Ioannou YA, Bishop DF, Desnick RJ. Overexpression of human-galactosidase. A results in its intracellular aggregation, crystallization in lysosomes and selective secretion. J Cell Biol. 1992;119:1137-50.

20. Eng CM, Guffon N, Wilcox WR, Germain DP, Lee P, Waldek S, et al. Safety and efficacy of recombinant human beta galactosidase A replacement Therapy in Fabry's disease. N Engl J Med. 2001;345:9-16.

\section{*Correspondência:}

Rua Amparo, nº 92 - Apto.300 - Barroca

Belo Horizonte - MG

CEP: $30.430-490$ 